\title{
Aging of engine oils and their influence on the wear of an internal combustion engine
}

New designs of internal combustion engines require the use of engine oils that can cope with more demanding conditions, primarily with greater loads and higher temperatures. The requirements of recent years have led to a wider use of modern base oils and specially designed additive packages. This avoids the formation of impurities and changes in viscosity as a result of shearing of the viscosity additives under high loads. The article discusses the important problem of oil aging during operation and the impact of this phenomenon on the operation of internal combustion engines. The influence of oil service life and its replacement on the emission of toxic exhaust gas components was discussed, and the results of research on the effect of oil service life on changes in their viscosity were presented.

Key words: combustion engines, engine oils, aging of engine oils, viscosity, selection

\section{Introduction}

The rapid development of the modern automotive industry in recent years implies the creation of new car designs, including, in particular, new, revolutionary drive systems. Suffice it to say that the number of cars in the world already in 2010 exceeded a billion, while at that time about 7.2 billion people. And in the not so distant year 1970, the number of vehicles in Poland was about 0.5 million - thus about 80 compatriots per 1 car. Today, around 7 people in the world are related to one vehicle. The huge supply of cars makes car concerns outdo each other in meeting the expectations of car buyers to attract customers, who choose a model not only based on the price, brand and color as it used to be in the past, but also engine power, fuel consumption and driving comfort. And in the engine there are extremely unfavorable operating conditions: combustion temperatures reaching even above $2000^{\circ} \mathrm{C}$, rotational speeds in a normal engine of $6000 \mathrm{rpm}$, i.e. $100 \mathrm{rpm}$. At these revolutions, the piston must cover the distance between the so-called cylinder blind spots 100 times per second! Its movement speed reaches $20 \mathrm{~m} / \mathrm{s}$.

An engine without proper lubrication breaks down very quickly or even gets destroyed. Therefore, for many years, oil companies have been working on the development of engine oil technology that will protect the engine against wear so that it can withstand hundreds of thousands of kilometers of mileage and years of operation. It will be possible if the oil fulfills the tasks set for it.

New designs of internal combustion engines require the use of engine oils that can cope with more demanding conditions, primarily with greater loads and higher temperatures. The manufacturers' strategy requires, among other things, an increase in boost pressure and advanced control of the combustion process and exhaust gas cleaning. This in turn causes the engine accessories to become highly complex and subjected to extremely high loads. All this affects the reliability and durability [2, 15]. This creates more difficult conditions for engine oils. The requirements of recent years have led to a wider use of modern base oils and specially designed additive packages. The use of oil bases with a higher viscosity index makes it possible to reduce the content of viscose-depressants. This avoids the formation of impurities and changes in viscosity as a result of shearing of the viscosity additives under high loads. The most important changes in newly produced engine oils are the selection of shear-resistant viscosifying compounds and lubricating additives, compatible with exhaust gas treatment systems and at the same time fulfilling their functions in conditions of high pressure and high temperature $[1,6]$.

Additionally, the gears mechanically account for approx. $7 \%$ of total fuel consumption. In rolling bearings, new types of seals and special plastic greases are used to reduce energy losses. Achieved savings are from 30 to $50 \%$ resistance to motion. In the case of mechanisms that work together without rolling bearings, the solution is to use gear or engine oils of correspondingly lower viscosity. Less common synthetic oils are also used in gearboxes, and carbon fibers instead of molybdenum and light metal alloys are more and more often used for the friction surfaces of synchronizers, which on the one hand reduce the weight of the mechanism, but on the other - are more susceptible to the transmission of vibrations.

\section{Aging of oils during exploitation}

The constant aging of the used oil is caused by the action of the oxygen contained in the air, which reacts relatively easily with the hydrocarbons. As a result of their oxidation, compounds with the structure of alcohols, aldehydes and organic acids are formed, resin products undergoing secondary condensation reactions in the form of hard-to-remove lacquers, deposited on the internal surfaces of the engine. This is accompanied by the simultaneous detachment of hydrogen atoms from hydrocarbon chains, which causes the formation of double bonds in them, which are the cause of parallel polymerization processes. After very long runs, the oil turns into thick, black tar, unable to lubricate anything, and in extreme cases - even into a solid. The oxidation process is accelerated by high temperature, as it causes thermal decomposition of base oil hydrocarbons, viscosity modifiers and some improvers $[4,5]$.

The operating conditions of engine oil determine its quantitative and qualitative consumption (especially the operating temperature affects the intensity of physicochemical changes, e.g. oxidation). The quality, composition, and physicochemical properties of engine oil are important engine operating factors that can largely affect the composition and emissions of toxic components formed in the en- 
gine's operating process. The effect of oil on these indicators is a complex and not fully understood phenomenon.

The influence of engine oil on the emission of toxic exhaust gas components also takes place by influencing the efficiency of catalytic exhaust gas treatment systems. The parameters of engine oils during the operation of the engine are not uniform and they change depending on the operating conditions, number of kilometers traveled, operating time, technical condition of the engine and its cooperating components. Any changes in the properties of lubricating oils that go beyond the lower and upper limit ranges adopted for them have negative effects in the form of possible damage and an increase in the emission of toxic exhaust components. Fig. 1 shows changes in oil properties during exploitation.

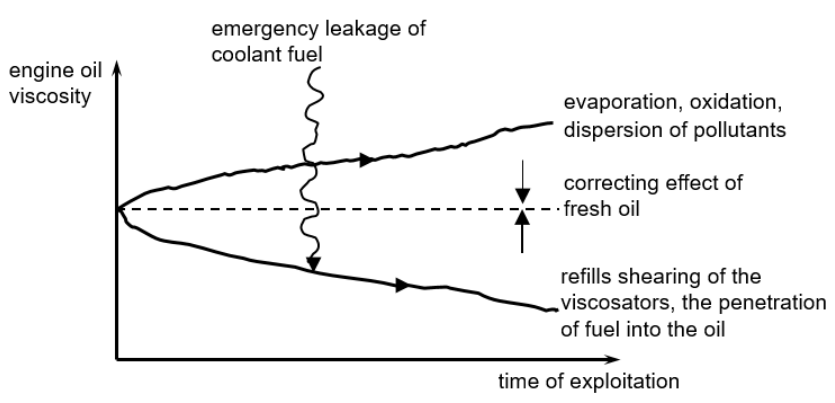

Fig. 1. Changes in oil properties during exploitation

The effects of improper oil durability or improperly set oil change cycles become visible later, during engine repair. When viewing its disassembled pistons, it is easy to determine the ease of formation and the type of contamination deposited thereon (Fig. 2).

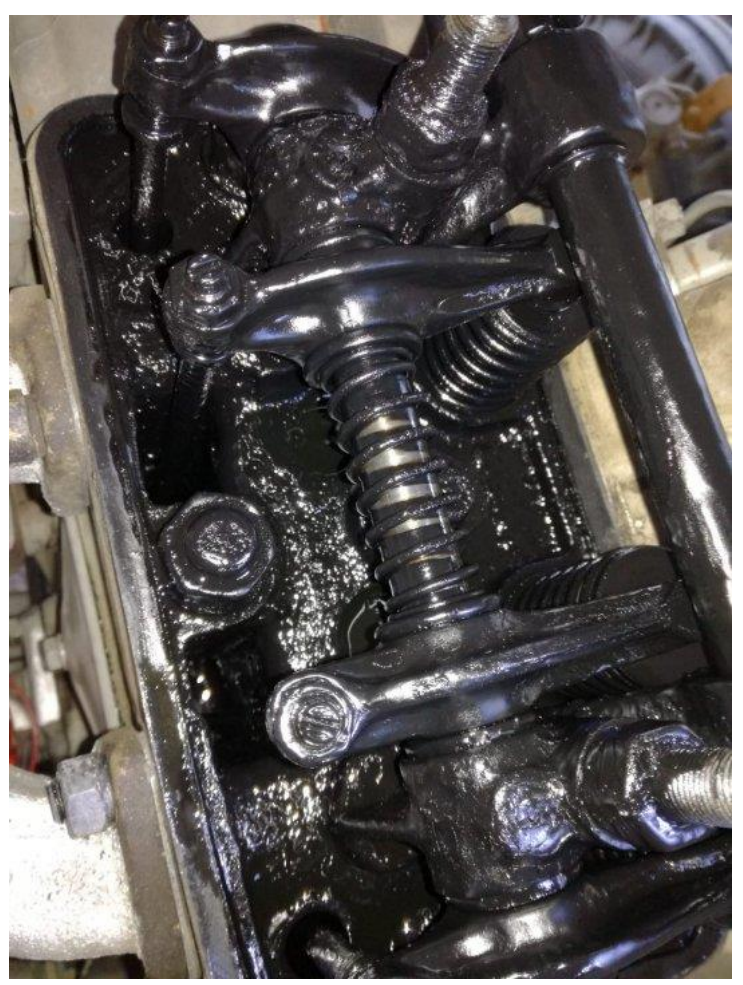

Fig. 2. Used oil in the engine
Therefore, it is extremely important to regularly replace used engine oil with fresh oil, which initially cleans the entire lubrication system, and then protects it for the rest of its operation. The oil filter must be changed at the same time, as it is only designed for a certain mileage. Then, although it does not block the circulation, it ceases to participate in it due to the so-called shunting. The extended mileage between oil changes recommended by various manufacturers is often not due to technical needs (defined as a standard around $15,000 \mathrm{~km}$ ), but for marketing reasons. American car makers, by no means obsolete, are even stricter in this regard, requiring a 4,000 to 6,000 mile $(7,200$ to $9,600 \mathrm{~km}$ ) replacement of their engine oil, in part due to the widespread use of more easily degraded cars in American mineral oils.

\section{Influence of oil exploitation time and oil change on the emission of toxic exhaust gas components}

Many studies on the impact of engine operation time with specific oils on their quality wear, i.e. oil aging, indicate their impact on the amount of toxic exhaust components emitted. The graphs (Figs. 3-5) show the results of the research [7] on the influence of the engine oil operation time on the emission of individual exhaust gas components and fuel consumption, as well as on how the amounts of the emitted components change after replacing with new oil. Oil aging, i.e. deterioration of its properties over time, but also, for example, engine operation conditions, the quality of the fuel being filled, the quality of the oil itself, the amount of contaminants in the engine, affect the time interval in which the engine oil is changed.

The graphs (Fig. 3-5) show two engine exploitation modes [7]:

- condition 1 - low load,

- condition 2 - medium load.

The horizontal axis of all graphs shows the engine again time and the oil again time. The graphs show fuel:

a - oil A, lower quality oil,

$\mathrm{b}-$ oil B, better quality oil.

The tests were carried out for a diesel engine with a capacity of $2.5 \mathrm{dm}^{3}$, turbocharged $92 \mathrm{~kW}$ and oils: A - mineral $15 \mathrm{~W}-40$, viscosity coefficient $135, \mathrm{~B}$ - synthetic $0 \mathrm{~W}-40$, viscosity coefficient 183 .

Figure 3 shows the influence of oil operating time on fuel consumption in the engine; it can be seen that oil B has narrower ranges of fuel consumption values, regardless of whether it is low or medium load operation. Both oils have a negative effect on fuel consumption and you can see that fuel consumption is on an upward trend, and when changing to a new oil, it returns to its initial state.

Figure 4 shows the effect of oil operation time on the emission of particulate matter - there is a large range of values of particles in the oil of lower quality at low load, while with B oil, these values are low and have little differentiation. After replacing the oil with a new one, the values for oil A slightly increase, while for oil B they even decreased. Figure 5 shows $\mathrm{NO}_{\mathrm{x}}$ emissions - nitrogen oxides at higher loads show higher values due to higher combustion temperature, while oil A at low load after working for 126 hours has quite a sudden increase in emissions, this may be due to poorer oil quality and the accumulation of pollutants, 
this means oil aging greatly affects the emission of nitrogen oxides.

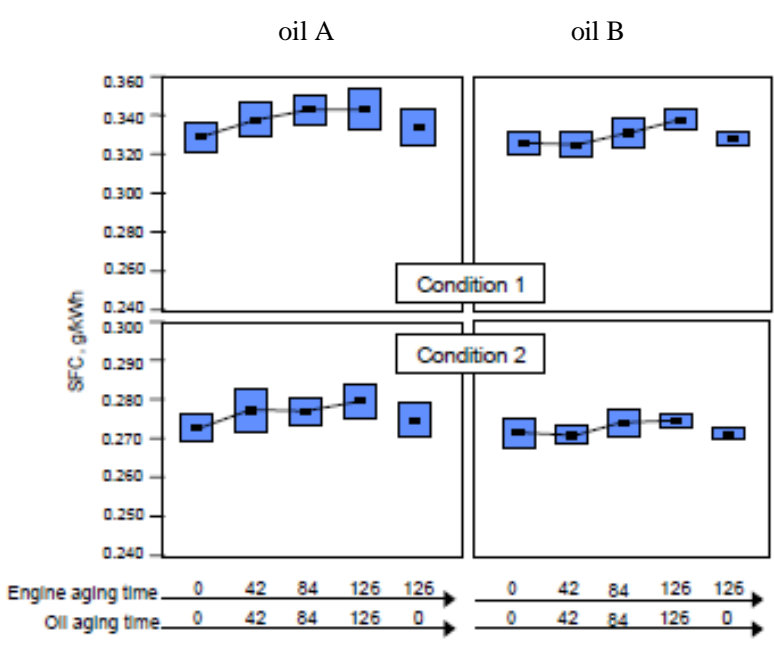

Fig. 3. Influence of oil operation time on fuel consumption

oil A

oil B

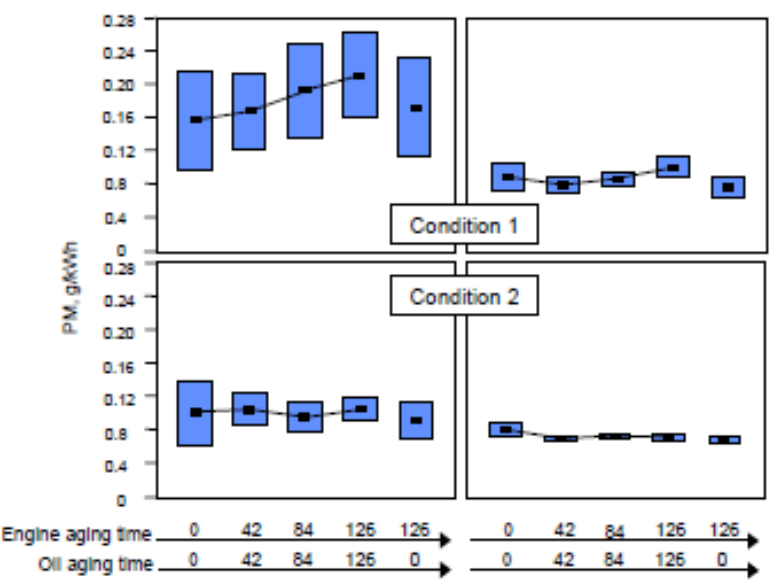

Fig. 4. Influence of oil operation time on the emission of solid particles oil A

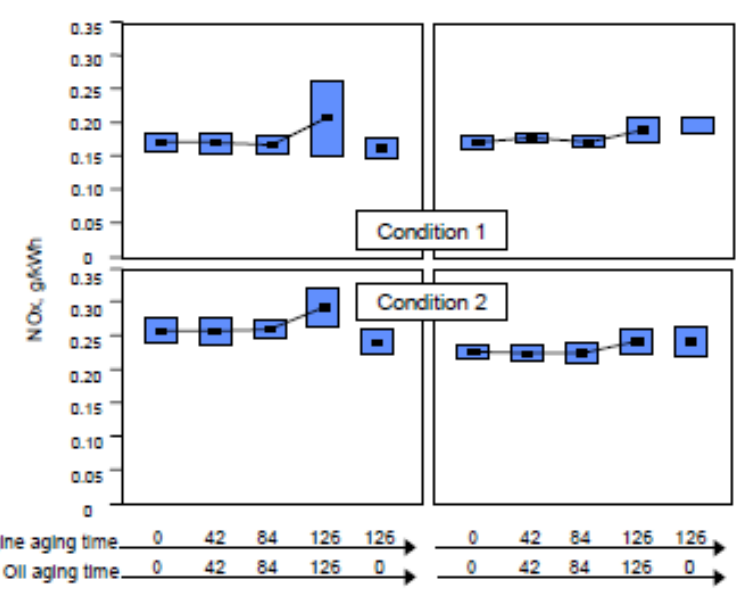

Fig. 5. Influence of oil operation time on the emission of nitrogen oxides

It follows that the use of synthetic oil contributes to the reduction of $\mathrm{NO}_{\mathrm{x}}$ and particulate emissions. The emission of nitrogen oxides is related to the content of aromatic hy- drocarbons, which also affect the density of the engine oil. Figure 5 shows that the use of mineral oils increases $\mathrm{NO}_{\mathrm{x}}$ emissions by about $8 \%$. In addition, the lower number of aromatic hydrocarbons characteristic of synthetic oil contributes to a better oil viscosity index.

\section{Research on the influence of oil exploitation time on changes of their viscosity}

The aim of the research was to determine the change in viscosity of engine oils depending on the mileage of a passenger car. LongLife oils were used for the tests, with a replacement interval every 30 thousand. $\mathrm{km}$. This type of oil was chosen because of its widespread use in modern internal combustion engines; Synthetic oils are used more and more because of their quality and positive influence on fuel consumption reduction. The issues discussed in the paper concern mainly the variability of viscosity depending on various factors $[11,15]$. Moreover, the types, properties and additives of motor oils have been presented quite extensively in order to study their relationship with the oil viscosity. Thanks to this, the obtained results can be considered in a broad aspect.

The test consisted in determining the viscosity of Castrol Edge 5W30 oil samples taken from passenger car engines with various mileage. All samples came from both petrol and diesel engines. Moreover, they were only turbocharged TSI or TDI engines, serviced at an authorized vehicle service station. As the samples come from engines with different powers and capacities, and the cars were driven by different drivers and under different conditions, the test results are indicative.

On the basis of the conducted research, the optimal mileage for LongLife oils used in petrol and diesel engines was determined to an approximate degree. This mileage is indicative, because the oil samples come from the engines of one brand of cars, serviced in authorized service centers, although used by different drivers. As the driving style and the main conditions of car use (urban, extra-urban, mixed traffic) also affect the consumption and parameters of the oil, it is impossible to determine the exact mileage at which an oil change should occur.

In the conducted tests, the kinematic viscosity of the engine oil was measured. The collected oil samples were selected based on similar mileages from petrol and diesel engines. Oils derived from gasoline engines were considered separately. In addition, the new oil was also tested to compare its parameters with the manufacturer's data. In the case where an oil sample was taken from an engine with less than 30,000 service mileage. $\mathrm{km}$, this was only done when the oil change warning light came on. Modern cars are equipped with an on-board computer with special software that keeps track of the car's driving statistics. Information on the number of actuations as well as the time and speed of travel is saved. On this basis, the computer estimates the mileage after which the oil should be changed. In a situation where the car is used primarily in city traffic, with a large number of stops, and the average speed does not exceed $50 \mathrm{~km} / \mathrm{h}$, the oil change indicator may light up after $7,000 . \mathrm{km}$. The oil samples were taken after the runs listed in Table 1. 
Table 1. The mileage after which samples of engine oils were taken

\begin{tabular}{|l|l|}
\hline \multicolumn{2}{|c|}{ Type of engine } \\
\hline Diesel & Petrol \\
\hline \multicolumn{2}{|c|}{ Mileage [km] } \\
\hline 10000 & 9800 \\
\hline 11200 & 11526 \\
\hline 15435 & 14000 \\
\hline 15800 & 14800 \\
\hline 21246 & 18200 \\
\hline 23150 & 19020 \\
\hline 23689 & 24533 \\
\hline 26108 & 25353 \\
\hline 29063 & 28900 \\
\hline 30000 & 29339 \\
\hline
\end{tabular}

Each sample was tested for kinematic viscosity at $19^{\circ} \mathrm{C}$ and $45^{\circ} \mathrm{C}$, and then the viscosity of the samples was determined at $100^{\circ} \mathrm{C}$. The test results with the calculated values are presented in the graphs in Fig. 6 and 7. For a more precise analysis of the viscosity changes for individual samples, the test results, together with the calculated values, are presented in the form of graphs on the above-mentioned drawings showing the kinematic viscosity as a function of temperature [7].

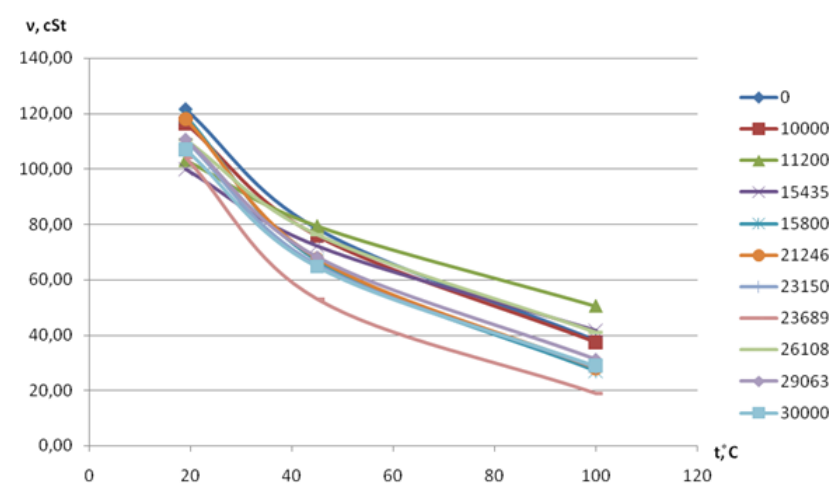

Fig. 6. Change in viscosity of oil samples taken from diesel engines depending on the temperature

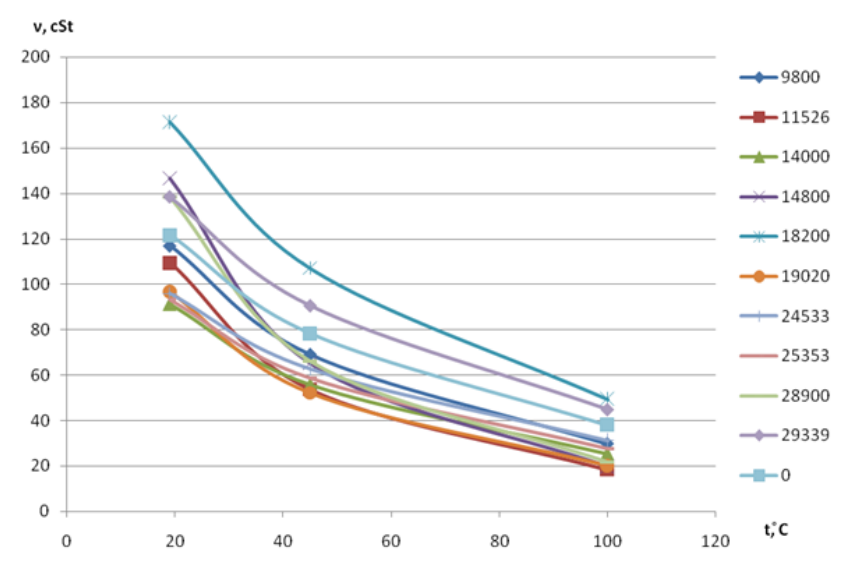

Fig. 7. Change of viscosity of oil samples taken from petrol engines depending on the temperature
When analyzing the above results, it is noticed that more than a twofold increase in temperature from $19^{\circ} \mathrm{C}$ to $45^{\circ} \mathrm{C}$ causes a decrease in viscosity by several dozen percent in both diesel and petrol engines. With regard to the maximum and minimum values, in diesel engines they are respectively $119.01 \mathrm{cSt}$ for $15,800 \mathrm{~km}\left(19^{\circ} \mathrm{C}\right)$ and $18,94 \mathrm{cSt}$ for $23,689 \mathrm{~km}\left(100^{\circ} \mathrm{C}\right)$, and for petrol engines $171.49 \mathrm{cSt}$ for $18,200 \mathrm{~km}\left(19^{\circ} \mathrm{C}\right)$ and $18.30 \mathrm{cSt}$ for $11,526 \mathrm{~km}\left(100^{\circ} \mathrm{C}\right)$. Thus, for the maximum value, the difference between diesel and petrol is as much as $70 \%$, and for the minimum value less than $4 \%$. Presumably the sample with a viscosity of $171.49 \mathrm{cSt}$ was from contaminated oil as the remaining petrol engine viscosities are much lower.

When looking at the graph for diesel engines (Fig. 6), it can be seen that the curves for individual samples have a very similar shape, so their percentage changes in viscosity are similar. The viscosity of the new oil varies from about $120 \mathrm{cSt}$ to less than $40 \mathrm{cSt}$. A sample with a mileage of $10,000 \mathrm{~km}$ has almost the same mileage. On the other hand, the sample whose mileage is the most different from the new oil curve is the one with a mileage of $23,689 \mathrm{~km}$. In addition, other samples, the viscosity of which at $100^{\circ} \mathrm{C}$ drops below $31 \mathrm{cSt}$, are samples with the following runs: $29,036 \mathrm{~km}, 30,000 \mathrm{~km}, 23,150 \mathrm{~km}, 21,246 \mathrm{~km}, 15,800 \mathrm{~km}$ and $23,689 \mathrm{~km}$. Among the samples with a mileage of more than $20,000 \mathrm{~km}$, only one $(26,108 \mathrm{~km})$ maintains its viscosity at $100^{\circ} \mathrm{C}$ at the level of $40 \mathrm{cSt}$. Moreover, the sample with a mileage of $15,800 \mathrm{~km}$ also has a low viscosity. This may indicate the need to change the oil no later than after $15,000 \mathrm{~km}$. On the other hand, the viscosity of the new oil at $100^{\circ} \mathrm{C}$ was determined by interpolation and not by testing. Hence the difference - according to the manufacturer, the oil viscosity at $100^{\circ} \mathrm{C}$ is about $13 \mathrm{cSt}$. However, assuming there is some constant interpolation error, comparisons can be made for all viscosities obtained by this method. It is also worth noting that none of the samples showed increased viscosity at $19^{\circ} \mathrm{C}$. This proves that there is a small amount of impurities that may increase the viscosity of the engine oil.

With regard to petrol engines, the samples taken from them have similar characteristics to those taken from diesel engines (Fig. 6). The chart shows that the sample with the mileage of $9800 \mathrm{~km}$ is the most similar to the new oil. Only two samples have higher viscosities than the new oil - these are samples with mileage of $18,200 \mathrm{~km}$ and 29,339 km. While the increase in viscosity in a sample with a mileage of less than $30,000 \mathrm{~km}$ is explained by a large amount of impurities, for a sample with a mileage $18,200 \mathrm{~km}$, justification should be sought in the difficult engine operating conditions. Most likely, the car from which the sample was taken was used mainly in typically urban conditions.

It is also worth mentioning that the sample curve with a mileage of $28,900 \mathrm{~km}$ is very steep, which is unfavorable due to large and quite rapid changes in temperature as a function of viscosity. Moreover, the oil with the mileage of $19,020 \mathrm{~km}$, which is not the oil with the highest mileage, has the lowest viscosity at $100^{\circ} \mathrm{C}$. It is possible that this oil has been diluted with gasoline that has entered the lubrication system. This can be thought because the viscosity of gasoline is only $1 \mathrm{cSt}$, so even a small amount of it can 
have a big impact on lowering the oil viscosity. This results in a difficult oil film formation and, consequently, even engine seizure.

In order to show how much dirt gets through despite the use of modern filters for engine oil, a photo was taken (Fig. 8) comparing (from left to right) oil from a petrol engine with a mileage of $29,339 \mathrm{~km}$, fresh oil and oil from a diesel engine with a mileage of $29,063 \mathrm{~km}$. You can clearly see how much not only the color of the oil has changed, but also how much sediment there is. The dark, almost black color of the oil is mainly influenced by solid particles, mainly composed of carbon. This is also a problem with modern petrol engines due to the use of direct injection.

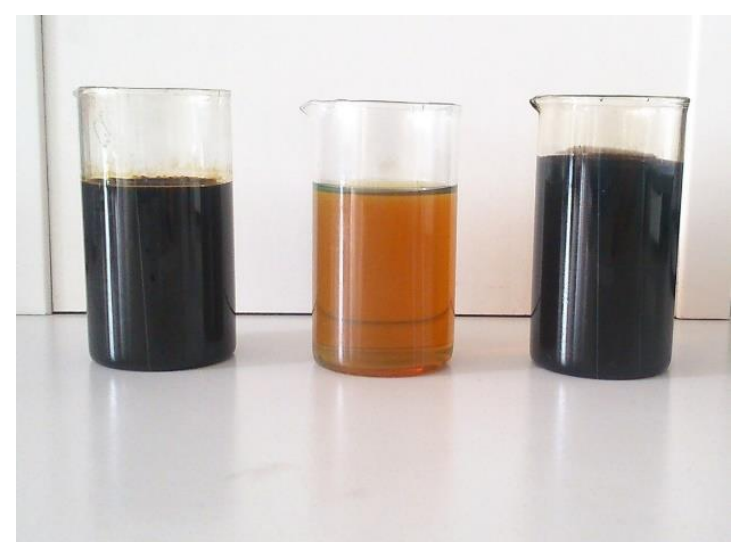

Fig. 7. Beakers containing (from the left) oil from the petrol engine $(29,339 \mathrm{~km})$, fresh oil and oil from the diesel engine $(29,063 \mathrm{~km})$

\section{Conclusion}

Requirements for internal combustion engines are increasing, especially in the face of offensive competition of electric drives. Therefore, engines are expected, above all, to increase their power, fuel consumption and toxic exhaust emissions. Because of this essential is the development of fuels and lubricants used in the operation of vehicles.

A visible trend in changing the properties of engine oils is the introduction of oils of lower and lower viscosity to the market. Lower viscosity results in reduced frictional resistance, but with decreasing viscosity, the ability to form an oil film in the friction junctions decreases. The viscosity of the oil mainly affects fuel consumption and improves the mechanical efficiency of the engine. Preliminary tests of engine oils marked SAE 0W-16, 0W-12 and 0W-8 showed an improvement in the performance of engines intended for the use of these oils. In the case of older engines, too low viscosity leads to boundary friction, and even in extreme situations to seizure of the friction nodes. This is due to the design of the new engines. They are specially designed to operate under less effective hydrodynamic lubrication conditions.

Manufacturers of internal combustion engines try to design them in such a way that they are adapted to oils of relatively low viscosity. On the other hand, such oils are so low in viscosity at high temperatures that in sports, loosely fitting engines, they can enter the cylinder and burn. In this case, the manufacturer provides oil consumption standards of up to $1 \mathrm{dm}^{3} / 1000 \mathrm{~km}$, but fuel consumption has a very detrimental effect on the environment. When comparing the test results for petrol and diesel engines, it is noted that while in the case of diesel engines it is possible to establish an approximate mileage at which the oil should be changed, for petrol engines it is practically impossible. For diesel engines, the curve closest to that of fresh oil is that of a sample with a mileage of $10,000 \mathrm{~km}$. In the case of samples from SI engines, the sample with a mileage of $9800 \mathrm{~km}$ has the most similar, although not overlapping, curve. However, the viscosity of this sample at $100^{\circ} \mathrm{C}$ is as much as $7 \mathrm{cSt}$ lower, therefore it is difficult to talk about similar values here. This may indicate how important the driving style of the driver and the area of use of a car with a turbocharged gasoline engine are on the quality of the oil. Probably one of the reasons for the rapid aging of the oil is the high temperatures in the engine. They are much higher than for supercharged diesel engines because the petrol engines achieve much higher RPM. As a result, the turbochargers in the petrol engines also have a higher RPM than in the diesel engines.

The problem of the selection of oils for internal combustion engines is also important in terms of environmental pollution - it is a topic that has been discussed very much and important in the last dozen or so years. The way internal combustion engines will be constructed in the coming years translates into pollution of our planet, therefore all possible solutions are used to meet the applicable exhaust emission standards. Anthropogenic pollution, i.e. manmade in the world, in relation to production processes, the municipal sector, agriculture, waste, energy used in industry, road transport has a significant share, in the case of carbon monoxide (CO) it is $22 \%$, and nitrogen oxides $\left(\mathrm{NO}_{\mathrm{x}}\right)$ is as much as $39 \%$. When choosing an engine oil, one should therefore follow the recommendations of the vehicle's engine manufacturer - each engine has a different structure, different sizes of channels through which the oil flows to the elements where a continuous oil film must be created so that the engine can operate with the highest possible efficiency. It is also good to use higher quality oils that have a higher purity of the base oil and further better lubrication parameters and a lower impact on exhaust emissions. Oil change in engines operated in intensive city traffic, in off-road conditions or on long and fast motorway routes, should be performed much more frequently than indicated by "average" or "extended" standards. A reasonable solution to this problem are the computer systems for assessing oil suitability for further use introduced by many manufacturers.

\section{Bibliography}

[1] AHMED, N., NASSAR, A. Lubricating oil additives. Egyptian Petroleum Research Institute. 2011. https://doi.org/10.5772/22923

[2] ANDREWS, G., HALL, J., RAHMAN, A. et al. The influence of an on line heated lubricating oil recycler on emissions from an IDI passenger car diesel as a function of oil age. SAE 
Technical Paper 2000-01-0232. 2000. https://doi.org/10.4271/2000-01-0232

[3] DEVLIN, M.T. Common properties of lubricants that affect vehicle fuel efficiency: A North American historical perspective. Lubricants. 2018, 6(3), 68.

https://doi.org/10.3390/lubricants6030068

[4] ANDREWS, G., ABDELHALIM, S., LI, H. The influence of lubricating oil age on oil quality and emissions from IDI passenger car diesels. SAE Technical Paper 1999-01-1135. 1999. https://doi.org/10.4271/1999-01-1135

[5] IDZIOR, M. Nowe metody rozwiązywania problemów współczesnych silników o zapłonie samoczynnym. Zeszyty Naukowe Instytutu Pojazdów Politechniki Warszawskiej. 2007, 3(66), 5-21.

[6] IDZIOR, M. Badanie wpływu przebiegu pojazdów na zmiany właściwości olejów silnikowych, Autobusy. 2016, 6.

[7] IDZIOR, M., WICHTOWSKA, K. Badanie wpływu przebiegu pojazdów na zmiany właściwości olejów silnikowych. Autobusy. 2016, 6.

[8] JEFFERD, K., ROGERSON, J., COPP, D. et al. The impact of lubricants on heavy duty diesel engine fuel economy and exhaust emissions. SAE Technical Paper 2000-01-1983. 2000. https://doi.org/10.4271/2000-01-1983

[9 LECHNER, G., KNAFL, A., ASSANIS, D. et al. Engine oil effects on the friction and emissions of a light-duty, $2.2 \mathrm{~L}$ di-

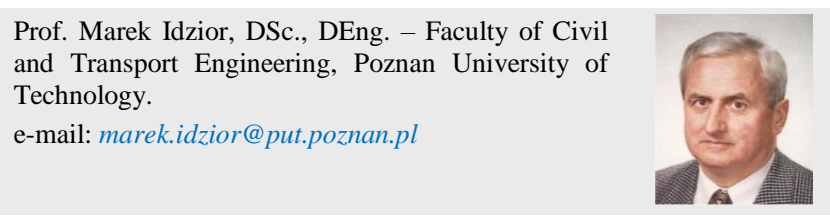

rect - injection - diesel engine. Part 1 - engine test results. SAE Technical Paper 2002-01-2681. 2002.

https://doi.org/10.4271/2002-01-2681

[10] MANNI, M., FLORIO, S., GOMMELLINI, C. Impact of fuel and oil quality on deposits, wear and emissions from a light duty diesel engine with high EGR. SAE Technical Paper 2000-01-1913. 2000. https://doi.org/10.4271/2000-01-1913

[11] MAMGBI, R., CERNY, J., BARIFAIJO, E. Time of exploitation and detergency properties of low SAPS engine oil. NaftaGaz, 2013, 69(1), 57-65.

[12] SMITH, T., KERSEY, V., BIDWELL, T. The effect of engine age, engine oil age and drain interval on vehicle tailpipe emissions and fuel efficiency. SAE Technical Paper 2001-013545. 2001. https://doi.org/10.4271/2001-01-3545

[13] TRIPATHI, A., VINU, R. Characterization of thermal stability of synthetic and semi-synthetic engine oils. Lubricants. 2015, 3(1), 54-79. https://doi.org/10.3390/lubricants3010054

[14] SP399-B-Facts about engine oils. The University of Tennessee Agricultural Extension Service. SP399B-1M-11/98(Rev)E122015-00-066-99. http://trace.tennessee.edu/utk_agexmach/5

[15] ZWIERZYCKI, W. Płyny eksploatacyjne do środków transportu drogowego. Wydawnictwo Politechniki Poznańskiej. Poznań 2006. 